\title{
Shifting Global Climate Governance: Creating Long-Term Goals Through UNFCCC Article 2
}

\section{P. Brian Fisher, College of Charleston}

Since our exit from Bonn (June 2011), the climate regime has taken significant steps toward developing short-range standards for global emission reductions based on a temperature threshold of $2^{\circ} \mathrm{C}$ above pre-industrial levels (UNFCCC 2010c). However, as the climate regime pursues a post-Kyoto agenda to establish specific greenhouse gas (GHG) targets, the question that now stands is how these short-term standards, fixed to a temperature threshold, fit into more holistic climate policy objectives. This article seeks to situate these short-term objectives within longer-term climate policy goals by examining five different approaches to developing climate architecture and policy. The conclusion is that the current approach based on national targets and timetables is insufficient to generate long-term equitable and efficacious climate policy.

Since the Bali Road Map ${ }^{1}$ was constructed, focus has been on what the IPCC (2007) established as a dangerous threshold temperature of $+2^{\circ} \mathrm{C}$ (IPCC 2007b; UNFCCC 2009; UNFCCC 2010b; UNFCCC 2010c). From Copenhagen in 2009 through Bonn 2011, the mitigation discourse has centered this threshold as the target for cultivating specific emission reductions. ${ }^{2}$ While the threshold has been agreed upon generally ${ }^{3}$ and

\footnotetext{
${ }^{1}$ A two-year plan to generate a legally binding agreement in Copenhagen in 2009 based on fixed national emissions targets.

${ }^{2}$ In addition, significant progress has also been made in concatenating the diversity of country reduction commitments and in developing more transparency in the monitoring, reporting and verification (MRV) processes.
}

PORTAL Journal of Multidisciplinary International Studies, vol. 8, no. 3, September 2011. Special issue details: Global Climate Change Policy: Post-Copenhagen Discord Special Issue, guest edited by Chris Riedy and Ian McGregor.

ISSN: 1449-2490; http://epress.lib.uts.edu.au/ojs/index.php/portal

PORTAL is published under the auspices of UTSePress, Sydney, Australia. 
some headway made, three critical issues have emerged that threaten the future of effective climate governance. First, mitigation in a post-Kyoto scheme is based on a 'pledge and review' system, where individual countries promise to cut emissions and agree to a monitoring of their progress. This pledge relies exclusively on the good intentions of individual countries to meet global emission goals, one that can be easily subverted or deprioritized, and subjected to traditional collective action dilemmas.

Second, there is no consensus and ambition to develop a 'shared vision' for longer-term commitments. The AWG-LCA (Ad hoc Working Group on Long-range Cooperative Action under the UNFCCC) explicitly directs, 'Parties share a vision for long-term cooperative action in order to achieve the objective of the Convention under its Article 2' (UNFCCC 2010b). Little has been accomplished since Kyoto in formulating this vision. In fact, long-term cuts in emissions and concentrations were excluded from consideration as part of the shared vision, and put on the agenda for COP 18 in Durban, South Africa in 2011 (WRI 2010). There also remains little in common between the developed and developing countries in mitigating emissions. Finally, there are no common targets to fulfill long-range objectives as outlined in Article 2 of the UNFCCC.

Third, there are significant issues in the implementation of emission controls to meet the $2^{\circ} \mathrm{C}$ temperature target. As it stands, current pledges are inadequate to reach this target. Specifically, the United Nations Environmental Programme (UNEP) concluded in Cancun (2010) that existing pledges only amounted to 60 percent of the greenhouse gas (GHG) emission reduction necessary to meet the $2^{\circ} \mathrm{C}$ target (UNEP 2010; see also, Levin and Bradley 2010). This leaves a critical gap in meeting the target itself. So, while the 'pledge system' may stimulate interest initially from China and the USA (whose emissions represent more than 40 percent of the global total), it also means that these two countries can hold the rest of the regime attendant to its national self-interests. Specifically, the universal nature of the current approach allows for certain countries to continue holding the regime hostage to its interests (Prins \& Rayner 2007).

Overall, while the focus has been on minimizing emissions to avoid this threshold temperature, scant attention has been paid to longer-term goals and approaches to reach

\footnotetext{
${ }^{3}$ Some within the regime, particularly those already vulnerable to climate changes like Small Island States, have advocated a $1.5^{\circ} \mathrm{C}$ threshold; however, many in the regime have countered that this is not pragmatically feasible.
} 
those goals. Despite the optimism surrounding the recent developments in climate governance, these issues raise important questions about the viability of the current global governance to meet the $+2^{\circ} \mathrm{C}$ target to prevent long-term climate disruption.

The thesis of this article is that existing deficiencies emphasize the need for long-term goals within the regime to guide short-term policy objectives. In many ways, the longterm trajectory is more salient to building and establishing effective climate policy than short-term objectives of national emission targets (Rayner 2010). As it stands now, the hope is that by meeting short-term goals, long-term consequences will be mitigated. I argue that this may lead to ineffective results. Without a clear set of long-term objectives to drive climate negotiations, 'ad hoc approaches and incremental decisions may prematurely foreclose options for protecting the climate' (Corfee-Morlot \& Hohne 2003) now and for future generations. In addition, this approach neglects to address the underlying drivers of climate change, that is, the systems, institutions, and discourses in which the problem itself is created. If these drivers are not addressed, the efficaciousness of climate governance will be limited. This possibly will exacerbate present global inequities, and create a subclass of displaced and vulnerable populations. In short, the current short-term approach does little to change the global structure in which the problem is embedded.

There are larger implications from this approach that are not extensively considered in literature or policies. Article 2 lays out the purpose of the climate regime, stating that the 'objective' is to avoid 'dangerous anthropogenic interference with the climate system' (italics mine). Article 2 hinges on how 'dangerous' is defined and what exactly constitutes the 'climate system' - that is, is it merely the biophysical changes in the atmosphere or does it include impacts that affect people? The current approach to climate governance renders the definition of 'dangerous' to be a simple function of limiting global GHG emissions to avoid exceeding the $2^{\circ} \mathrm{C}$ threshold. This short-term prescriptive approach sees the issue as purely an environmental problem that can be managed through technical solutions to limit national GHGs based on discretionary country pledges. This unnecessarily mischaracterizes the problems posed by climate change. In addition, despite recent progress in bringing climate adaptation into the discussions through the Cancun Adaptation Framework and securing pledges for funding (\$100B) over the next ten years (UNFCCC 2010c), there has been little 
practical global governance and implementation on large-scale adaptation. By treating climate problems exclusively as an environmental issue, the current adaptation structure treats the symptoms rather than the cause, ignoring other significant implications for policy.

Efficient and equitable climate policy cannot be achieved without first a definitional dialogue funneled toward developing long-term policy goals that should precede any short-range solutions. Hard targets may not be set, but particularly the USA and China must establish long-term goals; otherwise, short-term successes can be quickly undermined. Establishing long-term goals can offer multifarious approaches to meet those goals, rather than a direct, linear based on a 'one size fits all' approach that has led to the present inadequacies in climate governance. ${ }^{4}$ It also allows shifts in political and economic global structure to accommodate more equitable and effective institutional arrangements to meet the long-term goals.

While the objective of the regime should remain climate stabilization to avoid dangerous interference, it should not be done based on GHG targets. In this light, establishing long-term goals for climate policy is imperative and it must: (i) include differing paths for the differing circumstances of states, (ii) address the fundamental drivers of climate change, and (iii) address the 'effects' side of the equation based on the three pillars of sustainable development, i.e. social \& economic development, environment and climate protection and equity. Based on these critical elements, what follows will analyze various approaches to addressing the climate change problem to determine what may help establish long-term goals for the regime. Based on this, I argue for discarding national emission targets in favor of long-term goals based on renewable energy and enhanced security for those most vulnerable to climate impacts.

\section{Article 2 of the UNFCCC}

The history of Article 2

The core of the UNFCCC centers on Article 2, which outlines the objective of the agreement, and Article 3, which provides guiding principles to implement the Convention. These two Articles set up the remainder of the agreement, including the

\footnotetext{
${ }^{4}$ Domestically it requires constituents to buy into short-term political sacrifice for longer-term goalsgoals that they may or may not recognize as in their interest. This is particularly true for the USA. For key states like the USA, if domestic constituencies cannot support global policy on climate change, there is a serious risk of undermining the entire regime.
} 
commitments required by signatories, and a practical agenda on observations, education and training, future Conferences of the Parties (COPs), scientific bodies, and a financial mechanism. Since the early 1970s, the climate policy debate focused on how to stabilize GHG concentrations, and this aspect was enshrined in Article 2 as the core objective of the Convention. Article 2 (UN 1992) states, in full:

\begin{abstract}
The ultimate objective of this Convention and any related legal instruments that the Conference of the Parties may adopt is to achieve, in accordance with the relevant provisions of the Convention, stabilization of greenhouse gas concentrations in the atmosphere at a level that would prevent dangerous anthropogenic interference with the climate system [emphasis added]. Such a level should be achieved within a time-frame sufficient to allow ecosystems to adapt naturally to climate change, to ensure that food production is not threatened and to enable economic development to proceed in a sustainable manner.
\end{abstract}

Since the adoption of the UNFCCC, however, attention in policy circles gradually shifted to the near term, particularly to the development, ratification, and implementation of the Kyoto Protocol. Specifically, most developed countries have focused on mitigation targets in the Kyoto Protocol while developing countries have focused more on burden sharing than on Article 2 (See UNFCCC/SBSTA/2002/INF.14 2002; Blanchard et al. 2002; Oppenheimer \& Petsonk 2005). ${ }^{5}$ Recently, this focus continued in Copenhagen and Cancun with an attempt to generate post-Kyoto agreement for reducing GHG emissions through binding national targets. To date, a post-Kyoto agreement has not been reached, and binding national targets have been reduced to a 'pledge and review' system. These developments have led increasingly to a narrowing of focus by the regime to ensure: a) the viability of the regime itself; b) tangible short-term imperatives are agreed to; and c) attempt to build consensus on these objectives. However, this narrowing of concentration has also led to discounting longterm goals.

\title{
Questions arising from Article 2
}

Article 2 is indeterminate, as it 'conveys some degree of the substance of the long-term goal while carefully avoiding any quantitative expression of it' (Gupta \& van Asselt 2006: 83; Bodansky 1993). As a result, it raises critical definitional questions that inhibit determining long-term goals for addressing global climate change. Article 2 centers on the 'stabilization of greenhouse gas concentrations ... at a level that would prevent dangerous anthropogenic interference with the climate system' [emphasis

\footnotetext{
${ }^{5}$ In addition, the G77, including China, has objected to discussions of Article 2 for fear that it might lead to emissions caps for them (Corfee-Morlot \& Hohne 2003).
} 
added]. Three critical points can be made about this first half of Article 2. First, and most importantly, it is not at all clear what 'dangerous' means. Is there a specific level of danger associated with climate change that represents a trigger point for the biophysical climate system? Second, GHG concentrations become the de facto measuring stick for anthropogenic interference, and not for example, mean global temperature. ${ }^{6}$ Third, who is in danger? - that is, is it a measure of targets and timetables, or danger to regions, or specific locales and peoples?

How these fundamental questions are approached, and ultimately answered, brings a host of critical, secondary issues to the fore. These point to the role of 'climate impacts' in the climate governance equation, prompting three questions. First, where along the causal path is 'danger' or risk to be measured? Second, how do we regulate and manage 'anthropic interference with the climate system'? Third, how is 'climate system' defined (that is, what constitutes the 'climate system' that is in danger)? These questions prompt a second set of questions. How is 'danger' or risk to be measured; in other words, at what point in the climate cycle do we measure what is dangerous to the climate system? How do we govern the danger or risk? That is, do we address GCC by adjustments in emissions reductions through mitigation and trading, the process itself (by empower decision making), the structures that create the material and ideational underpinnings of GHG emissions (e.g. an energy revolution), or the impacts? Is it a combination? To date, there has been but one approach - mitigation through national targets (or now 'pledge and review') with an increasing discourse around adaptation. Finally, what is included in the climate system? Is it simply a measure of environmental or more specifically atmospheric danger, or regional or local climate systems that then impact people? Does the definition include how people are affected by changes in the climate system? Who is prioritized, if at all, within the 'climate system'? These questions are imperative for developing future climate policy.

Where we are today on Article 2

Since the inception of the UNFCCC, most of the activity on Article 2 has focused on the scientific and economic aspects of GHG concentration stabilization. Early on, the IPCC

\footnotetext{
${ }^{6}$ There is criticism about the use of GHG concentrations as the measuring stick for slow climate change, primarily because there is no fixed quantifiable measure for anticipating future or anticipated GHG emissions. See, for example Victor (2001). In addition, as the language has shifted to the $2^{\circ} \mathrm{C}$ threshold, it seems to run counter to the Article 2 standard.
} 
interpreted Article 2 by seeing GHG 'concentrations stabilization' as a function of national emissions that aggregate in generating future temperature and sea level changes (Wigley 1995; Wigley et al. 1996; Oppenheimer \& Petsonk 2005; Schellnhuber et al. 2006). Therefore, from this early stage, much of the discussion focused on emission stabilization pathways on the mitigation side of the climate equation, and has 'largely bypassed the explicit consideration of climate change impacts' (Corfee-Morlot \& Hohne 2003). Moreover, these 'stabilization pathways' were primarily considered from the perspective of aggregate national emissions. In fact, since 1997, international climate negotiations were dominated by short-term issues such as the design of rules of the Kyoto Protocol (Corfee-Morlot \& Hohne 2003). Even today (through Cancun and Bonn 2011), the discourse continues to center around emission targets and timetables.

Similarly, the focus on what constitutes 'danger' has focused primarily on scientific and economic considerations, while social, cultural and ethical dimensions have received scant attention (Rayner \& Malone 1998; Adger 2001; Elzen \& Berk 2003; Gupta 2003; Oppenheimer \& Petsonk 2005; Gupta \& van Asselt 2006; Fisher 2011). In addition, the psychological aspects of 'danger' remain dormant within a climate change context (Kasperson et al. 1988; McDaniels et al. 1996; Henry 2000). That is, to the degree impacts were discussed, much of it focused on those direct biophysical impacts with global consequences, such as ice sheets (that would contribute to sea level rise), global coral bleaching, and the economic costs of these types of impacts and of mitigation. In 2001, the third assessment report by the IPCC restructured their thinking on Article 2 by referring to 'five areas of concern,' including: (i) risk of large scale singularities; (ii) aggregate impacts; (iii) distribution of impacts; (iv) risks of extreme weather events; and (v) risks to unique and threatened systems. Nevertheless, the "climate change policy debate in the last few years has focused more on the costs of mitigation than on the avoided impacts or potential benefits of mitigation' (Corfee-Morlot \& Hohne 2003: 277-278). Although recently there has been increasing attention to adaptation, particularly in light of economic development, the negotiation calculus for large emitters continues to focus on the costs of mitigation, rather than avoided impacts and/or the impacts to those most vulnerable. Simply, negotiations are driven by costs and economics. This is even more so after the 'pledge and review' system adoption, since key countries can use their discretion on GHG reductions and to what degree they will comply. 
In this regard, in the most recent IPCC AR4 report (2007), contributors drew upon Article 2 directly in a call to determine 'key vulnerabilities' (IPCC 2007d: 784). For the first time, there was a specific call for scientific assessment of what impacts might be associated with different levels of GHG concentrations, and 'normative evaluation by policy-makers of which potential impacts and associated likelihoods are significant enough to constitute, individually or in combination, DAI [Dangerous Anthropic Interference]' (IPCC 2007d: 784). As a result, today Article 2 and 'key vulnerabilities' are one of the seven crosscutting themes for all working groups (Patwardhan et al. 2003; Oppenheimer \& Petsonk 2005).

As the IPCC AR4 and the Cancun Agreements (UNFCCC 2010c) demonstrate, there is increasing dialogue on vulnerability and adaptation. However, the discussions remain at the periphery of climate policy, which remains driven by mitigation through national emission targets to reduce global GHGs. The goal of this policy approach is to prevent global mean surface temperature from exceeding another $2^{\circ} \mathrm{C}$, after which many scientists agree certain key tipping points in the climate system may be triggered. However, despite this near consensus on beyond $2^{\circ} \mathrm{C}$ temperature target, there remains uncertainty on what amount would prevent triggering dangerous tipping points. Thus the policy plan is based on reaching short-term targets and hoping that it is enough to achieve this $2^{\circ} \mathrm{C}$ goal.

\section{Operationalizing UNFCCC Article 2}

The climate process: How it works

At the global level, dynamics of IPAT, population growth, affluence and technology contribute to degradation of the biosphere. These drivers have tentacles reaching into the national and local levels influenced by more complex drivers of poverty, urbanization, land use, income distribution, values and governance ideology. These global drivers contribute to the structure that facilitates activities that generate GHGs. These drivers merge and combine with anthropogenic drivers at the local level and individual level (see Figure 1). There, anthropogenic drivers of GHG emissions take place within national and global contexts. These 'agency' drivers include fossil fuel burning (transportation, refrigeration, and so on), increasing waste in landfills, land use (for example, deforestation, rice paddies), and industrial processes (such as cement 
production). ${ }^{7}$ In addition, individual environmental values play an important role in supporting and justifying these material practices that lead to GHG emissions. These individual anthropogenic drivers lead to an accumulation of GHG emissions that enter the biophysical climate cycle, which then 'force' or produce local biophysical climate impacts such as changes in temperature, precipitation, and sea level rise (SLR). These climate changes impact human populations, which can be positive or negative, depending on sociopolitical and economic structure as well as geography. For many, particularly in vulnerable regions, this impact will be negative and will result in some form of human and societal impact (see Figure 1 below). ${ }^{8}$

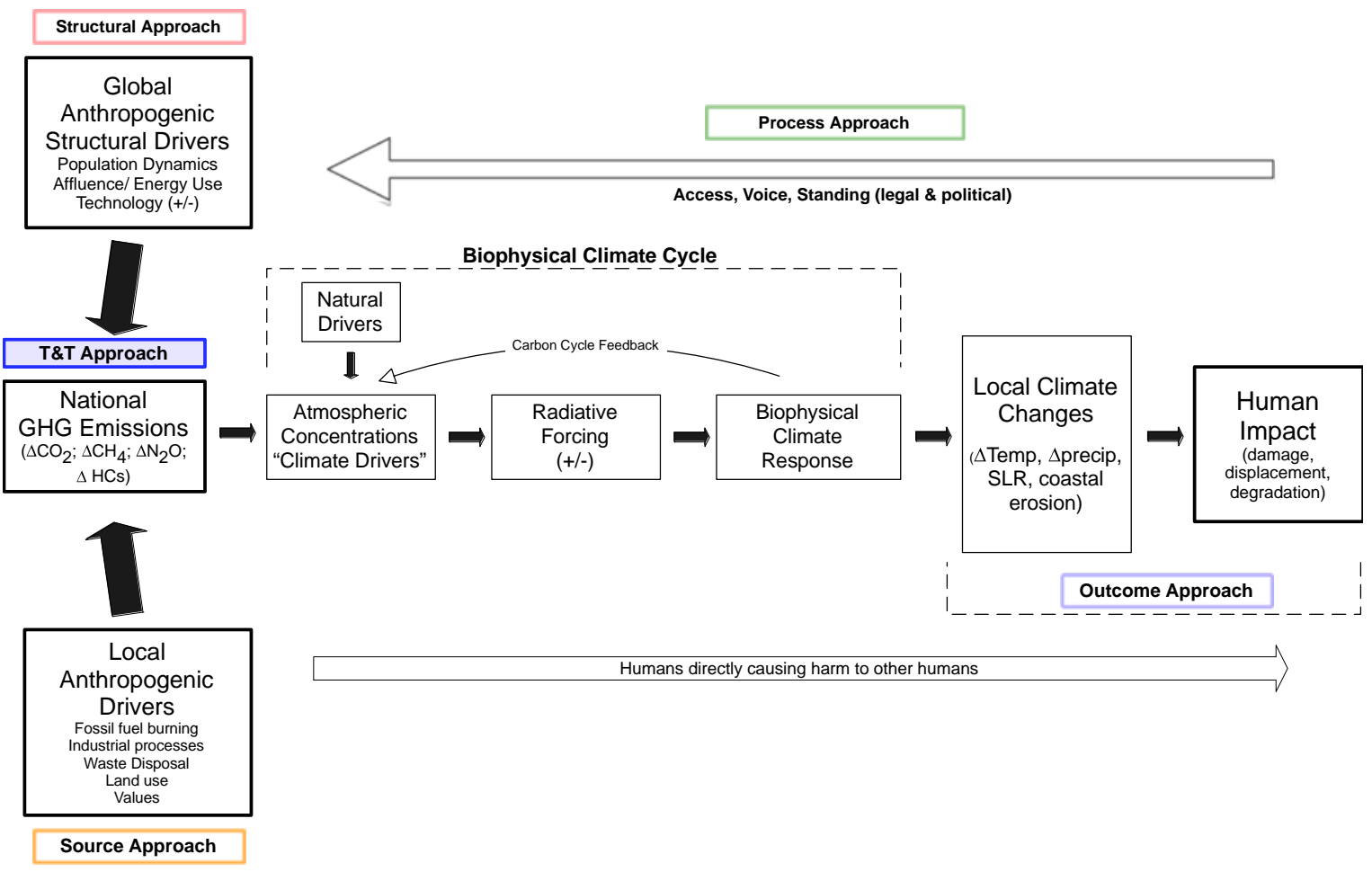

Figure 1. A linear depiction of the 'climate process.' This figure illustrates the full range of the climate process and how humans cause direct harm to other humans through the medium of earth's climate system. It also represents the five (5) policy approaches to address fuller range of the climate problem.

\footnotetext{
${ }^{7}$ Structural drivers at the local level are different from IPAT at the global level and include policy, institutions, organizations/NGOs, culture/traditions, social factors (such as family), and so on.

${ }^{8}$ I do not necessarily see the 'climate process' as a linear cause-effect, as depicted in this figure, but it helps to demonstrate where in the process may be most effective in addressing climate change.
} 
Approaches to climate governance: Framing the 'Big Picture'

A fundamental question for climate governance is where along the cause-effect chain provides the most effective and equitable position to address climate change (see Figure 1). The UNFCCC and recent climate agreements assert climate change must be addressed in part through sustainable development. Sustainable Development, it is argued by the UN, is a three-sided equation of equity, environment, and economic development - the 3 E's. I will examine five possible approaches to address climate change (as depicted in Figure 1) in light of UNFCCC Article 2 and the three pillars of sustainable development.

\section{The targets and timetables approach}

The first approach is best characterized by the Targets and Timetables (T\&T) approach (see Table 1). Currently, the UNFCCC, Kyoto Protocol (KP), and the Cancun Agreements (CA) all seek to regulate GHG emissions as the primary source of climate change at the national level. Based on this approach, the Kyoto Protocol commits developed countries to reduce GHG emissions to target limits. The single largest advantage of this approach is that it is already in use by the UNFCCC and IPCC (Torvanger et al. 2004: 9). A second significant advantage is that it works within the current constructs of the state-based international system. So the incentive system runs parallel with the state-based system, providing rules and norms that help guide, implement, and to some extent, enforce GHG emissions' mitigation through binding global agreements supported by domestic mechanisms. Thus, this approach holds the state responsible for determining and implementing its own mitigation mechanisms to reach target emissions. A third advantage is that it is empirically calculable. A fourth advantage is that it is only one step removed from individual behavior (person, firm, plant, or corporation) that generates emissions. This reduces the level of uncertainty and enhances the validity of empirical measurements. Finally, as technology changes, new technical options are easily implemented to mitigate emissions, creating an attractive synergy between national governments and corporations that incentivizes new technology.

There are significant drawbacks to this approach, however. First, and most importantly, it relies heavily on the current international system, which is subject to severe disparities in power and leverage. The structure inherently serves the interests of the dominant 


\begin{tabular}{|c|c|c|c|c|c|}
\hline & Source & $\begin{array}{c}\text { Targets \& } \\
\text { Timetables } \\
\text { (T\&T) }\end{array}$ & Structural & Process & Outcome \\
\hline Description & $\begin{array}{c}\text { Regulate } \\
\text { individual } \\
\text { activities that } \\
\text { produce GHGs }\end{array}$ & $\begin{array}{l}\text { Regulate at the } \\
\text { national source } \\
\text { of GHGs }\end{array}$ & $\begin{array}{c}\text { Regulate Global } \\
\text { Political \& } \\
\text { Economic } \\
\text { Systems }\end{array}$ & $\begin{array}{l}\text { How int'l } \\
\text { decisions are } \\
\text { made in } \\
\text { regulating } \\
\text { commitments }\end{array}$ & $\begin{array}{l}\text { Regulate based on } \\
\text { effects of CC }\end{array}$ \\
\hline Examples & $\begin{array}{l}\text { Individual } \\
\text { allotments }\end{array}$ & $\begin{array}{c}\text { National GHG } \\
\text { emissions }\end{array}$ & $\begin{array}{c}\text { Address } \\
\text { dynamics of } \\
\text { PAT } \\
\text { (pop, tech, \& } \\
\text { affluence) }\end{array}$ & $\begin{array}{l}\text { International } \\
\text { negotiation; } \\
\text { participation; } \\
\text { markets }\end{array}$ & $\begin{array}{l}\text { Impacts of climate } \\
\text { change on local } \\
\text { populations (e.g. } \\
\text { adaptation) }\end{array}$ \\
\hline $\begin{array}{l}\text { Level of } \\
\text { Focus }\end{array}$ & $\begin{array}{l}\text { Local/Individual/ } \\
\text { Corps: individual } \\
\text { emissions }\end{array}$ & National & $\begin{array}{c}\text { National \& } \\
\text { Global }\end{array}$ & Global & $\begin{array}{l}\text { Local/community: } \\
\text { impacts on } \\
\text { community }\end{array}$ \\
\hline Advantages & $\begin{array}{c}\text { * Addressing } \\
\text { fundamental indiv } \\
\text { drivers of GCC; } \\
\text { * attacks 'values' } \\
\text { underpinning } \\
\text { behavior } \\
\text { * Provides } \\
\text { common ground } \\
\text { * allows for clean } \\
\text { technology to } \\
\text { address the core of } \\
\text { emissions }\end{array}$ & $\begin{array}{c}* \text { GHG } \\
\text { emissions are } \\
\text { source of GCC } \\
* \text { calculable } \\
* \text { In use (IPCC) } \\
* \text { step close to } \\
\text { emissions } \\
* \text { bring in } \\
\text { corps/tech }\end{array}$ & $\begin{array}{c}\text { * addresses } \\
\text { structural driver } \\
\text { of GCC } \\
* \text { inherently } \\
\text { builds on equity } \\
\text { considerations } \\
* \text { problems in } \\
\text { both poor \& } \\
\text { affluent } \\
* \text { considers the } \\
\text { global feedback } \\
\text { impact of GCC }\end{array}$ & $\begin{array}{c}* \text { focus is on } \\
\text { means of } \\
\text { producing equity } \\
* \text { fairer } \\
\text { participation }= \\
\text { fairer outcome } \\
* \text { those most } \\
\text { effected have } \\
\text { voice \& standing } \\
\text { (access) } \\
\text { * Rawls: welfare } \\
\text { of the worst-off } \\
\text { nations } \\
\text { maximized }\end{array}$ & $\begin{array}{c}\text { * Fairer burden- } \\
\text { sharing } \\
* \text { prevents longer } \\
\text { term problems } \\
\text { * ensures most } \\
\text { vulnerable } \\
\text { covered } \\
\text { *helps to redress } \\
\text { structural } \\
\text { inequities } \\
\text { *polluter pays }\end{array}$ \\
\hline $\begin{array}{c}\text { Dis- } \\
\text { advantages }\end{array}$ & $\begin{array}{c}* \text { Equity }= \\
\text { egalitarian? } \\
* \text { Unrealistic for } \\
\text { historic GHG } \\
\text { emitters } \\
* \text { emasculates } \\
\text { sovereignty } \\
* \text { need structural } \\
\text { equality at same } \\
\text { time }\end{array}$ & $\begin{array}{c}\text { * subject to } \\
\text { power in int'l sys } \\
\text { * distant from } \\
\text { 'real' impacts } \\
* \text { no } \\
\text { consideration of } \\
\text { global impacts }\end{array}$ & $\begin{array}{c}* \text { becomes a } \\
\text { function of GDP } \\
* \text { same int'l } \\
\text { deadlock issues } \\
* \text { execution - } \\
\text { Welfare system? }\end{array}$ & $\begin{array}{c}* \text { negotiation } \\
\text { about leverage \& } \\
\text { thus subject to } \\
\text { power } \\
* \text { state's interest } \\
\text { paramount }\end{array}$ & $\begin{array}{c}* \text { Increases costs } \\
* \text { inhibits climate } \\
\text { action } \\
* \text { builds a case for } \\
\text { compensation/ } \\
\text { damages }\end{array}$ \\
\hline
\end{tabular}

Table 1. Differing approaches to the architecture and development of climate policy.

powers. This has led to fractious negotiations that have ended in entrenched, seemingly intractable, positions by various states and their collaborative partners. Second, this represents only a short-term perspective for addressing climate change, with consequent solutions designed to slow the global GHG emissions that may trigger irreparable harm (which as discussed is the current medium-run goal of the regime). 
A third disadvantage is that it remains far removed from the effects and consequences of climate change. In fact, this approach offers no calculus of climate impacts, making it a highly inequitable policy approach for those who will suffer from significant climate effects. Because GHG emissions cannot be simply turned off, and even in the best mitigation scenario will continue through inertia, this approach has significant inequity built into it for those vulnerable to climate change impacts. In addition, this approach does little to address either the drivers of climate change and the political and economic structure in which climate change takes place. Thus, it entails deep structural inequity.

A fourth disadvantage is that it counts emissions based on the source of production and not consumption. This creates inequitable results because it provides a secondary incentive to locate the highest GHG producing activities in the poorest states. Already for economic competitive advantage, the 'dirtiest' production plants and firms are located in these areas, which overall tend to be the most vulnerable to environmental change. In essence, this provides cheap goods to the affluent with little or no environmental cost. In fact, people largely assume the environmental cost where the plant or industry is located through degradation and increased emissions, which could offset positive economic development in developing countries. Therefore, this approach creates a double incentive to locate these activities in poor states because powerful national governments would want the GHG emissions to be counted against least powerful states (with the power to do it). ${ }^{9}$ Incentives converge for both national governments and corporations to locate high GHG emission-producing plants in developing countries generating severe inequity. Only by counting the GHGs where the good is consumed can climate policy generate equitable and economic benefits in line with sustainable development. However, this is not the case with the $T \& T$ approach.

\section{The source approach}

A second approach characterized by the source approach focuses on individual or local level emissions as the foundational drivers of GHG emissions. That is, peopleindividually, in communities or as part of corporations, produce and use fossil fuels that augment global GHG levels contributing directly to GCC. This approach would regulate those activities at the local level. This approach can take many forms, from emission

\footnotetext{
${ }^{9}$ This is only offset under the targets and timetables approach to the degree that CDM in the KP works to share of technology through clean energy programs in these countries.
} 
taxes, fuel standards, promoting clean energy use, or 'contraction and convergence, ${ }^{10}$ in which global emissions are reduced by reducing per capita (or individual) GHG emissions. ${ }^{11}$ Both the precautionary principle and principles of equity underscore some form of per capita approach to stabilizing and ultimately limiting GHG emissions. The advantages of a source approach are that it is inherently based on principles of equity and thus has a strong justice component that will appeal to a variety of states for many reasons. Specifically, a 'contraction and convergence' (C\&C) policy is based on egalitarian criteria; that is, theoretically every person has the right to pollute to the same extent (and implicitly to be equally protected from pollution) (Meyer 2000; den Elzen et al. 2006). Even global fuel or energy standards are undergirded by egalitarian principles, preserving justice as a primary force in climate policy. Yet, it should be noted that historical responsibility, a highly debatable aspect of climate ethics, remains outside the scope of C\&C (Oberheitmann 2010). ${ }^{12}$ Second, at this individual/local level, the drivers of climate change are addressed at its most fundamental level - the industry or energy producer and the individual as the consumer of fossil fuels. This is the only approach that directly addresses the values that support environmentally degrading behavior.

Most importantly, clean energy technology can be applied at this level both to reduce emissions at the extraction/production site as well as at the consumer level. This provides a direct link to generating GHG reductions at the base level and does so as part of a long-term goal. In the current $T \& T$ approach, this is a tertiary goal—driven by the primary goal of reducing emissions at the national level. Here, the primary goal and focus of the regime is upon developing core technologies that can be used to produce cleaner energy, and use this cleaner energy in homes and buildings thereby enhancing efficiency, effectiveness, equity and security. Finally, it does offer some common ground for getting recalcitrant (yet differently positioned) countries like the USA and China to join in the global effort to combat global climate change, both through an incentivized approach based on technology and clean economies, as well as long-term

\footnotetext{
10 'Contraction' is the reducing of global GHG emissions, and 'convergence' is the closing of the gap between per capita emissions between the affluent and the developing countries to a level (in the future) where ultimately emission outputs are equal for every person. The total budget of carbon is to be equally shared through 'entitlements' based on a negotiable rate of linear convergence by an agreed upon timeline. ${ }^{11}$ C\&C was first formally proposed to the UNFCCC at COP-2 in 1996 by the Global Commons Institute, and at Copenhagen (2009) became a controversial subject. As expected, it lacked support among developed countries.

12 The 'Brazilian Proposal' allocated national emission limits based on historic responsibility, which is based on the polluter pays principle (See, Meira Filho \& Gonzalez Miguez 2000).
} 
goal of recognizing per capita emissions. For example, China already supports $C \& C$, while the USA may be enticed by incentives that reduce their obligations (initially) toward contraction with higher investment in clean energy. If this technology and clean energy were shared with the developing world, this would further soften the ground for agreement. This could actually build common ground, rather than feebly attempting to 'find' common ground, around long-run per capita emissions for states with divergent interests.

The primary disadvantage of the source approach is that it may be unrealistic for historic GHG emitters, who would have to consent (through international negotiation) to it—something that to date is rare in international politics. At this point, without technology to guarantee low per capita emissions, historical emitters may resist even soft long-term targets for several reasons. First, there may be a greater chance to bridge the China-USA gap through this approach than the $T \& T$ approach, particularly if tethered to clean energy incentives. Second, it emasculates sovereignty and a nation's control over its territory and citizens, which is historically a particularly hard sell for countries like the USA and China. In this regard, it is extremely doubtful that any progress could be expected on C\&C or GHG emissions per capita except as a nonbinding long-term goal without other incentives. Third, enforcement would be a challenge, because it requires the state to hold individuals accountable for greenhouse contributions - a highly unlikely scenario. Fourth, it is difficult to implement if the structural conditions that lead to global economic inequality are not addressed concomitantly. Finally, it is also difficult to standardize between countries and is dependent then on the incentives to develop technology outside of the formal climate architecture.

\section{The structural approach}

A third approach is a structural approach, where the focus of addressing climate change is on the structures that create and perpetuate GHG emissions. This approach addresses the underlying structural drivers of emissions leading to climate change. It would regulate climate change through changes to the political and economic systems at both the global and national scale. The primary advantage of this approach is that it attempts to get at the structural and institutional impediments to addressing climate change. For example, this approach would examine traditional structural dynamics leading to 
environmental degradation, such as population increases, technology, and affluence. This leads to a second advantage in that it seeks to recognize the extent to which each state is contributing to the problem regardless of socio-economic starting point (based on GDP). Theoretically, this is formed upon equity grounds; however, it would ultimately turn on whether historical antecedents for socio-economic conditions and population growth were concomitantly taken into consideration. Another significant advantage is that it recognizes global climate change as a process that continually influences and changes the political and economic structure. So part of this calculus considers the feedback of biophysical processes from climate changes upon the macro human subsystem.

There are serious drawbacks to the structural approach. First, in many ways it relies heavily on GDP for determining responsibility toward climate change. As a result, it would not differ much in international negotiations from the current $T \& T$ approach and thus have the same limitations. Second, if climate change is seen as a problem of structural drivers, then attending to those institutional drivers becomes a complex problem - one that may be as complex as the climate problem itself. For example, addressing trade disparities, conditional loans and investment streams that favor developed countries, is a complex and highly politicized debate. Increasing consumption in both developed and rapidly developing countries is another example - a significant issue that has been left off the discussion table altogether. Yet the climate problem is embedded within these structural disparities. Finally, addressing climate change through structural adjustments runs the risk of appearing as a welfare system designed to funnel financial and technological resources from the developed to the underdeveloped in a way that seems separate from the impacts of and responsibility for climate change. Most likely, these are fatal flaws that would lead to intractable collective action problems. However, the structural approach does demonstrate that addressing emission reductions and adaptation without attending to the structural drivers merely treats the symptoms of the climate problem.

\section{The process approach}

A fourth approach centers on the process and/or procedure through which international decisions are made in regulating commitments. The focus is on the international negotiation process, participation in the global environmental decision-making, access 
to information and data, and the market as a medium for addressing GCC. The biggest advantage of this approach is that those who are (or will be) adversely affected by climate change have both a voice and presumably some form of standing (that is, access) to the international system to redress their vulnerabilities, impacts, and damages from climate change. A second distinct advantage is that it can produce procedural justice by focusing on the means of generating policy. A third, related advantage is, in principle, that there is a correlation between fair participation and de minimus fairer outcomes. Finally, Rawls's maxim (1971) is implicit in this approach in that the welfare of the worst-off nations should be maximized, and thus operate as a net benefit to the poorest nations. ${ }^{13}$ Although Rawls did not endorse use of his theory directly as an argument for economic redistribution in the international arena, and instead confined it to a single society, it represents a specific justice approach to climate change that is not only relevant to generating equitable policy but one that cannot be ignored (Rawls, 1999:106). Henry Shue argues that through this process, the well off should not be enriched at the expense of the not so well-off, thereby expanding inequality (Shue 1999). Finally, it offers a platform for discussing burden sharing, and how to spread the costs of mitigation and adaptation (See, Shue 1999; Meyer \& Roser 2006; Page 2008). A distinct advantage of this approach is therefore that it highlights inequality in deriving decisions as well as in the outcomes of decisions.

The disadvantage of the process approach is that ultimately negotiation (at any level) is about leverage, and thus is about power. Power in the international system is inherently unequal, giving little leverage for those disenfranchised. Similarly, the international system continues to be dominated by sovereignty and state self-interest, which again diminishes procedural aspects of standing and access for those disaffected by climate changes. Moreover, the powerful can use bargaining tactics to undermine collective action. As Henry Shue points out, many countries such as the United States (and now China) are employing a strategy of waiting for others to do their 'fair share' before they will agree do the same, resulting in paralysis (Shue 2011). So, the powerful can manipulate the procedural process through which climate outcomes are negotiated,

\footnotetext{
${ }^{13}$ This theory is here applied generally to the international arena in the climate context. The argument here is that fundamentally distributive justice (in theory) lacks the capacity of imposing differing obligations between the domestic and international arenas, as 'nationality' would be an arbitrary characteristic similar to innate talent, race or social status. In addition, this process approach would not necessitate direct wealth redistribution, but a duty to assist those who are directly affected by human induced climate change, and to do so to the extent of full reparations.
} 
leading once again to unjust outcomes. This suggests that representation and standing do not necessarily guarantee an efficient or equitable outcome for parties, and may be ineffectual as a global instrument. In addition, a voice without standing (political or legal) has little meaning, and further without a legal structure or venue to protect access, the procedural approach may make little difference in outcome. Finally, this approach cannot represent a stand-alone approach to climate policy; in fact, it must operate as a complement to another approach.

\section{The outcomes approach}

Finally, the fifth approach is one based on outcomes of climate change. That is, climate policy is developed by examining the effects of GCC, particularly in local communities and specific contexts. The most compelling rationale supporting the outcome approach is that, because there are multiple ways to achieve just and efficacious climate policy, it offers a more diverse platform for equitable burden sharing (Rayner 2010). Second, there are underlying legal and political justifications for this approach, as GHG emission inputs (by human beings) are a direct causal force in harming both the environment and other human beings. ${ }^{14}$ This causational link moves the GCC issue into a sphere of justice that demands (in some form) the outcome approach (that is, adaptation). This argument is strengthened by two other variables-disproportionality and predisposed vulnerability. Climate change has locally disproportionate effects on those already marginalized and vulnerable (Pielke et al. 2007; Fisher 2011), and this approach acknowledges and addresses this important aspect of the climate problem. Third, this approach emphasizes dealing with the consequences of climate change, which will help mitigate additional unintentional effects, like the loss of culture and sovereignty, and climate-related diasporas that post a threat to the global community and economy, and to individual states. Fourth, this approach includes forms of bottomup, context-driven adaptation, but also compensatory justice, providing for broader prescriptions and forms of reparations from the damages caused by GCC. Fifth, contrary to the other approaches, this approach does not necessarily require international consensus to work or to build new institutions out of whole cloth. Sixth, the outcome approach breaks down the state-based formula necessary within the $T \& T$ approach and allows for vulnerable populations in developed countries, like impoverished sectors in

\footnotetext{
${ }^{14}$ Admittedly, proving specific causation, legally or even politically, is a significant issue, but one that does not subvert the argument here.
} 
the USA or the Inuit (in the USA, Canada, and Russia), to be recognized based on how they are affected by climate change. Finally, making the outcome approach, more than any other, has the potential to galvanize (Rayner 2010) because all parties need to adapt and build more resilient societal spaces. All in all, by including a fuller range of costs, an outcome approach changes the GCC calculus in ways that provide a more accurate reflection of the GCC problem and its consequences.

The major disadvantage of this approach is that it raises the perceived 'costs ${ }^{\prime 15}$ of GCC, which create clear disincentives to broadening the approach to GCC. Although perceived costs do not include costs to the environment, vulnerable communities, security, or the costs of 'doing nothing'. Second, a pure 'justice' angle rarely generates political action that counters national self-interest. A third drawback would be getting the global community to recognize climate impacts for those most vulnerable and to adequately fund adaptation. The proposed US\$100 billion for adaptation in the Cancun Agreements does not come close to the amount deemed necessary for large-scale adaptation globally (Stern 2009). In addition, global financial constraints and political perceptions of the climate issue suggest that as more resources are devoted to mitigation to prevent $2^{\circ} \mathrm{C}$, less will be devoted toward adaptation. This 'pendulum of costs' is beyond the scope of this article, but it does provide a potentially significant limitation to the outcome approach. This stresses the importance of incentivized connection with another approach that properly incentivizes the development of clean energy with climate adaptation. Finally, 'cost' calculi represents a Pandora's box, as who determines what is a climate-related impact, to what degree is it climate-related, who gets the money (what hierarchy), and who collects and distributes it with the capability of monitoring to ensure its proper use? These questions are not fatal flaws, but they point to significant impediments to international agreement and future climate policy.

\section{Reframing the approach to climate governance}

Changing the climate change frame: Justifying outcome and source approaches

In evaluating the five approaches, the key question is not so much about mitigation or adaptation as it is how much of climate change can (and should) be accepted. In the

\footnotetext{
${ }^{15}$ I say perceived costs here, because multifarious and significant costs are associated with GCC, far beyond mitigation costs and/or even adaptation costs, such as the damage to culture, indirect costs to local or national economies, or even administrative costs (at all levels). However, to date, the singular focus of climate negotiation has been on national level mitigation costs.
} 
language of Article 2, the question is how much climate change can be endured yet avoid DAI ('dangerous anthropic interference'). Today, mitigation and adaptation are considered in separate spheres or more recently as 'two sides to the same coin.' That said, much of the discussion and policy remains based on the $T \& T$ approach toward mitigation (that is, regulating GHG emissions at the national scale). This becomes an economic question - how much climate mitigation can be afforded? In this short-term view, economic self-interest will prevail over the environmental considerations, at least until such environmental costs become more apparent and significant or economic interests align with environmental ones. This directly suggests that, even at the national level, it is economically rational to delay action until those costs become increasingly clear or until new technology develops. The success of the regime, even if fully implemented, is then completely dependent on the degree to which technology provides answers. Even with motivation toward developing clean development technologies, finding cooperative arrangements when varying states have different historical responsibilities, capacities, political ideologies, and goals is difficult. In other words, the $T \& T$ approach in many ways inhibits economic motivation from being fully pursued and realized. It politicizes the climate regime and inhibits both market incentives and fails to address the human security of vulnerable peoples. As a result, at the global level the targets and timetables strategy inspires various forms of free riding, as larger national economies can continue business-as-usual without any additional economic costs, ${ }^{16}$ while others suffer the consequences. Without long-term goals and assessments, this free riding remains and national economic self-interest and externalizing economic and environmental costs become the driving forces of the climate regime.

However, when the question is changed to ask how much of climate change can (and should) be accepted by the global community, the calculus changes. I am not suggesting that nations will not continue to view climate policy through a lens of self-interest.

Rather, climate change is a global problem that creates changes in global climate, and thus to solve it requires a global perspective - not a conglomeration of national perspectives. This global perspective is further justified by two elements, one that humans are directly and disproportionately affected by the actions of other humans, and second, that the earth's biosphere is a global commons that all human beings are entitled

\footnotetext{
${ }^{16}$ Some scholars may suggest that economic opportunity costs arelost by delay, particularly in developing renewable energy technologies, and has been suggested, there are many who suggest that the long-term consideration of climate change has present economic costs of delaying action now (Stern 2007).
} 
to enjoy free of harm. On the former, the disproportionate effects create not only severe inequity but also serious security risks at the national and global levels.

In shifting the question to a global perspective and away from national self-interest, the foci of the problem itself are transformed in two ways. First, it includes those adversely affected by climate change and therefore brings the outcome approach to the fore, and second, the question emphasizes some form of an approach that is best for the global community, and not exclusively based on state self-interest. The emphasis then is on a source approach, one that may focus on creating clean energy and new technologywhich can be employed to the benefit of the global community. Simply put, this is a global problem affecting all nations (and people) and solutions should benefit all nations and the global community. This approach transforms the climate debate into a positive sum game.

When outcomes and sources are included in climate policy discussion, the calculus for mitigation is also changed. That is, adaptation becomes a cost of mitigation, and more emphasis is put on preventing the damage caused by human augmented GHG emissions (to reduce the costs of adaptation). So, if mitigation is solely part of the economic calculus, then for self-interested individuals, the equation is simple: is the harm from global climate change (to themselves or community) greater than economic costs of mitigation? Most in the USA see little harm from GCC to themselves personally, and therefore any economic cost is likely too high. However, if adaptation is part of the cost equation - that is, harm to others caused by GHG emissions, then the costs of doing nothing increase and becomes part of tradeoff analysis for climate policy. Action to prevent future harm (and costs) becomes imperative. In this form, justice emerges naturally from the cost equation, not as a function of strict national mitigation and/or historic responsibility. In addition, it provides political justification for domestic policies on climate change, particularly for the USA. As such, this is the core strength of the outcome approach to global climate change. Even further, this can be incentivized through the source approach based on developing clean technologies.

\section{Assessing 'danger' in Article 2}

The threshold question from Article 2 for long-term climate policy centers on assessing (i) DAI - dangerous anthropogenic interference with the climate system, and (ii) what are the subject(s) of the prevention. In preventing DAI with the climate system, the 
question becomes: what is the mandate designed to prevent or protect? Most scholars and policy makers have interpreted this aspect of DAI to mean the establishment of formal mechanisms designed around stabilizing national emissions by the largest polluters to ultimately 'stabilize' global GHGs to prevent a $2^{\circ} \mathrm{C}$ increase. Thus the regime has advocated and promoted for the last 20 years the $T \& T$ approach to climate policy. The argument here is not to dismiss informal mechanisms and/or formal monitoring of national GHGs, but rather, that this approach as the core of the regime misses the mark. Rather, the source approach, particularly when long-term goals are considered, offers a more substantive and effective path forward for the regime. It places energy at the center rather than aggregated emissions and targets and timetables. This offers more pragmatic pathways to generating effective GHG mitigation and international agreement.

On the second question - what is climate policy designed to protect from DAI, closer examination of the secondary aspects of Article 2 provides some insight. Specifically, Article 2 states (in the second part) that the ceiling for global GHG emissions should be kept at a level 'to allow ecosystems to adapt naturally to climate change, to ensure that food production is not threatened and to enable economic development to proceed in a sustainable manner' (UN 1992). The focus here is on maintaining global GHG concentrations at a given level to allow natural ecosystem adaptation, not threaten agricultural production, and promote sustainable development. The question is whether Article 2, in establishing the purpose and goal of the regime, included consideration of the impacts from climate change, and if so, to what degree and in what form should we consider the effects from climate change as part of the core mandate of the climate regime?

Considering the whole of Article 2, should concentrations (through radiative climate forcing) reach a level where changes to the ecosystem outpace adaptation and/or threaten food production, it would indeed constitute 'dangerous' interference with the climate system. This provides an initial clue that the framers were thinking to include 'impacts' to human support systems when drafting the Article. In fact, in some parts of the world - for example, atolls, the Arctic, lowlands of Africa-we are already seeing the pace of changes outstrip natural adaptation, food production, and adaptive capacity. In addition, much of international environmental law (IEL) has evolved primarily based 
on the norms that states are responsible for 'transboundary harm' from activities within their dominion and control. ${ }^{17}$ This principle of IEL that states are responsible for transboundary harm reinforces that states should be theoretically responsible for climate impacts. This, in conjunction with anthropogenic interference with the climate system that threatens food production implies that climate impacts must be part of the initial design of Article 2.

Article 1 of the UNFCCC (UN 1992) also provides guidance on 'adverse effects of climate change' as it states:

'Adverse effects of climate change' means changes in the physical environment or biota resulting from climate change which have significant deleterious effects on the composition, resilience or productivity of natural and managed ecosystems or on the operation of socioeconomic systems or on human health and welfare.

As part of the Convention, Article 1 suggests concern for socio-economic and health aspects of climate impacts, not just biophysical impacts (See Jamieson 1992, 1996; Rayner \& Malone 1998; Adger 2001; Gupta et al. 2003; Gardiner 2006). In addition, Article 4.1(f) asks all parties to minimize adverse climate effects on: '[T] he economy, on public health and on the quality of the environment, of projects or measures undertaken by them to mitigate or adapt to climate change' (UN 1992, UNFCCC Article $4(1)(f))$.

However, despite this reading of Article 1, there has been less attention to the socioeconomic aspects as a source of 'danger' in discussions on Article 2. Rather, the 'political and diplomatic process through which it evolved paid much more attention to physical and biological vulnerabilities as sources of danger, and rather less attention to economic issues ...[while] ethical and cultural considerations have been nearly absent' (Oppenheimer \& Petsonk 2005: 213). Clearly if there are socio-economic considerations as part of 'danger,' the broader aspects of human systems, i.e. cultural, ethical and psychological, must also be part of the calculus.

\footnotetext{
${ }^{17}$ See the Stockholm Declaration, Principle 21, which is echoed in the Rio Declaration, Principle 2: 'States have in accordance with the Charter of the United Nations and the principles of international law, the sovereign right to exploit their own resources pursuant to their own environmental policies, and the responsibility to ensure that activities within their jurisdiction or control do not cause damage to the environment of other States or of areas beyond the limits of national jurisdiction.' Principle 21 has now become customary law, which means that it applies to all states and not only states to a particular agreement. In IEL, see: Trail Smelter Arbitration (United States v. Canada), 3, United Nations Reports of International Arbitral Awards 1911 (1938), reprinted in 33 A.J.I.L. 182 (1939), 3, United Nations Reports of International Arbitral Awards 1938 (1941), reprinted in 35 A.J.I.L. 684 (1941).
} 
In further support of this interpretation, the final sentence of Article 2 gives significant primacy to 'sustainable development.' Although this could be an attempt to privilege economic development relative to climate change and environmental harm, it nevertheless demonstrates a linkage between climate 'danger,' its outcomes (effects), and sustainable development (Brundtland 1987). Given the history of sustainable development and climate change, the nexus between sustainable development- defined by the WCED as 'development that meets the needs of the present without compromising the ability of future generations to meet their own needs' - and climate change fit naturally with the ideas of stabilizing future concentrations and preventing dangerous outcomes - particularly for future generations (Oppenheimer \& Petsonk 2005). This emphasizes the three Es of Environment (protection), economic (development) and equity (fairness in process and substance) as part of climate governance. Reading both the precepts of sustainable development in line with Article 1 of the UNFCCC strongly suggests that not only would DAI include climate impacts, but it would also include socio-economic, cultural, and health (mental, emotional and psychological) impacts in addition to the biophysical ones (IPCC 2007d; Schneider et al. 2001). To include these necessary elements therefore endorses the outcome approach to climate policy.

\section{Article 2: A 'danger' to whom?}

What remains unanswered, however, is what a 'danger' is to whom and how should those 'in danger' be assessed? Here, there is no easy answer. A single, absolute metric of 'dangerous anthropic interference' cannot be attained due to differential impacts and vulnerabilities (Dessai et al. 2003, 2004; Schneider 2001, 2004; Jacoby 2004).

Moreover, 'dangerous' is a socially constructed term that requires knowledge of local context to understand how these impacts and vulnerabilities contextually play out. In determining DAI, value judgments are necessary to determine who is affected. Such value judgments are context specific (Dessai et al. 2004) and imply judgments about selection, comparability and significance, which in turn suggest that peoples' perceptions play a large role in defining ‘dangerous' (see, generally, Azar \& Sterner 1996). In other words, 'various societies and peoples may value the significance of impacts and vulnerabilities on human and natural systems differently' (IPCC 2007d: 784). For example, a resource-dependent society will value protecting its resource base more than most developed countries, and will thus prioritize the risk or 'danger' to those 
resources. As a result, biophysical indicators cannot sufficiently capture that communities - particularly those with different socio-economic positions, will be affected differently by the same level of climate change, and therefore they will not share the same meaning of 'dangerous.'

Finally, the choice of scale is 'also crucial, as considerations of fairness, justice and equity require examination of the distribution of impacts, vulnerability, and adaptation potential, not only among, but also within groupings' (IPCC 2007d: 784; Jamieson 1992; Gardiner 2004). Thus in operationalizing Article 2, examining how climate impacts affect people in a local context, and how people perceive those risks associated with climate change are critical features in determining DAI. These aspects of climate policy and policy discussions are understated in negotiations and understudied in climate scholarship.

This suggests that DAI is both how people are contributing to GHGs that change the biophysical climate system, but also how people are affected by these changes in climate and how they perceive that their exposure to the danger (posed by climate changes) has been augmented. As a result, before there can be a logical first step toward defining DAI at the global level, it must be understood from a climate impact perspective at the local level, including people's perception of risk. Therefore, longterm goals for equitable global climate policy (in meeting the objective of the UNFCCC as outlined by Article 2) can only be attained by understanding locally derived conditions that assess and establish 'risk' and DAI. A second insight from these approaches to DAI is that it provides a cogent argument for establishing long-term goals and targets around DAI, which help guide near-term decisions on mitigation commitments under the Convention (Corfee-Morlot \& Hohne 2003) as well as protect the most vulnerable by understanding their exposure to climate changes in their local context (Fisher 2011).

\section{Conclusion: Implications and consequences for climate governance}

I have argued that by establishing long-term goals for climate policy we can deduce more effective short-term climate policy (instead of the current approach of starting with short-term goals and moving forward). This requires understanding the tangible threats from climate change and recognizing synergistic linkages for incentivizing climate action. It necessitates reframing the political problem of global climate change 
to define 'dangerous anthropogenic interference' with the climate system in identifying those threats.

Developing long-term goals to address these threats from global climate change depends in large part on defining and operationalizing elements of UNFCCC Article 2. In attempting to operationalize Article 2, I showed that there are several stages in the causal process where climate changes could be measured, monitored and addressed by the regime. Currently, the regime has adopted the $T \& T$ approach to address climate changes, which has been shown to be politically difficult in international negotiations, particularly considering China and the USA are reluctant to engage in national emissions caps. Without addressing the unsustainable drivers of GCC, this approach may not address effectively the climate problem even if fully implemented. It also runs the risk that it may exacerbate current global inequalities, which places additional emphasis on developing a climate architecture that includes fair distribution of the responsibility and burdens from climate change. However, despite the proliferation of literature on burden allocation, from a policy perspective, it is very difficult to negotiate and get self-interested actors to comply with agreed-on parameters.

One of the primary risks from climate change to global (and national) economic and political systems is the increasing cost from growing insecurity and inequity. Both elements provide a challenge to the global system, a risk that is underrepresented in current international negotiations and climate policy calculi. Instead of climate security, responsibility and equity framing the climate debate, it has been mischaracterized as a singular environmental issue using the $T \& T$ approach. Climate change however is not a function of environmental degradation per se, but rather a function of unsustainable drivers of human development that represents significant threats to human systems, particularly those most vulnerable. This explains why traditional environmental methods and solutions have been ineffective in addressing the climate problem.

Therefore, the climate regime must replace the $T \& T$ approach with a combination of outcome and source approaches. By adopting these approaches, it essentially splits mitigation and adaptation into two separate strategies. The first is based on energy transformation and sources of emissions, where major polluters, the USA and China, can build common ground. By focusing on energy transformation will deviate each country from the business as usual path, while bypassing what may be an intractable 
problem of fair allocation and responsibility. The second is an explicit focus on adaptation because as currently constituted in the regime, adaptation is a secondary priority to mitigation.

The source approach shifts the focus away from national GHG emissions' limits to the development of clean energy toward long-term goals of carbon neutrality and (relatively) equal per capita emissions. In operationalizing this aspect of Article 2, it establishes targets based on the development of clean energy and renewable energy implementation (and targets), which can be more effectively integrated into an incentivized climate regime as well as address directly the drivers of GHG emissions. This approach also offers synergies and incentives for the USA and China to cooperate. Both countries recognize that 'green growth' is a key to the future of economic development, and both recognize not only the harmful effects to ecosystems and humans from industrial processes, but also that energy systems must be transformed. In addition, energy targets could be integrated into a system of contraction and convergence that allows for higher emissions, at least temporarily, the more funding and research put into energy development. This would create more equitable framework, based on contracting emissions per capita, while emphasizing energy transformation. The source approach therefore is a bridge between the seemingly growing gap between China and the USA, as well as bridges the divide between developed and developing countries. It provides a path forward where none exists currently based on the T\&T approach.

This shift would also recognize, through the outcome approach, the need to protect those most immediately threatened by the effects of climate change. It was established that this includes climate impacts more generally, and includes not only biophysical effects but also socio-economic, cultural and psychological effects. Next, this process should be examined at the local level and by studying how people are affected by a combination of causal and consequential pathways. These macro-approaches to climate change would be more effective in both addressing the drivers of GHG emissions (rather than based purely on outcomes) and provides clearer incentives to climate action. They also work together to create a more equitable approach (a mandate from both UNFCCC regime and sustainable development), both normatively in establishing longterm non-binding goals as well as empirically through active protection of the most 
vulnerable as a function of security — not merely as a handout or opaque notions of justice. ${ }^{18}$ In the final analysis, creating long-term goals with guideposts built around the source and outcome approaches is critical not only to creating an efficacious and equitable climate architecture but to the policy and governance of the issue.

\section{Reference List}

Adger, W. N. 2001, 'Scales of Governance and Environmental Justice for Adaptation and Mitigation of Climate Change,' Journal of International Development, vol. 13, no. 7, 921-931.

Azar, C. \& Sterner, T. 1996. 'Discounting and Distributional Considerations in the Context of Climate Change,' Ecological Economics, vol. 19, 169-185.

Blanchard, O., Baumert, K.A., Perkaus, J.F., \& Llosa, S. 2002, Building on the Kyoto Protocol: Options for Protecting the Climate. World Resources Institute, Washington, DC.

Berkes, F. \& Jolly, D. 2001, 'Adapting to Climate Change: Social-ecological Resilience in a Canadian Western Arctic Community,' Conservation Ecology, vol. 5, no. 2, article 18. Online, available: http://www.ecologyandsociety.org/vol5/iss2/art18/ [Accessed 1 Sep. 2011].

Brundtland, G. 1987, Our Common Future: The World Commission on Environment and Development. Oxford University Press, Oxford.

Corfee-Morlot, J. and Höhne, N. 2003, 'Climate Change: Long-term Targets and Short-term Commitments,' Global Environmental Change, vol. 13, 277-293.

den Elzen, M. G. J., \& Meinshausen, M. 2006, 'Multi-gas Emission Pathways for Meeting the EU $2^{\circ} \mathrm{C}$ Climate Target,' In Avoiding Dangerous Climate Change, (eds) H. J. Schellnhuber, W. Cramer, N. Nakicenovic, T. Wigley, \& G. Yohe. Cambridge University Press, Cambridge.

Dessai, S., Adger, W.N., Hulme, M., Turnpenny, J., Kohler, J. \& Warren, R. 2004, 'Defining and Experiencing Dangerous Climate Change,' Climatic Change, vol. 64, 11-25.

Douglas, B., Kearney, M. S., \& Leatherman, S. P (eds). 2001, Sea Level Rise: History and Consequences. Academic Press, San Diego.

Elzen, M. D. \& Berk, M. 2003, 'How Can the Parties Fairly and Effectively Establish Future Obligations under Long-term Climate Objectives?', in Climate Policy for the 21st Century: Meeting the LongTerm Challenge of Global Warming, (ed.) D. Michel. Center for Transatlantic Relations, Johns Hopkins University, Baltimore, MD, 113-151.

Fisher, P. B. 2011 (forthcoming), 'Climate Change in Tuvalu: The effect of Marine Ecosystem Changes on Human Security,' Global Change, Peace and Security, vol. 23, no. 3.

Gardiner, S. M. 2004, 'Ethics and Global Climate Change,' Ethics, vol. 114, 555-600. 2006, 'A Perfect Moral Storm: Climate Change, Intergenerational Ethics and the Problem of Moral Corruption,' Environmental Values, vol. 15, 397-413.

Goklany, I. M. 2002, 'From Precautionary Principle to Risk-risk Analysis,' Nature Biotechnology, vol. 20, 1075.

Gupta, J. 2003, 'Engaging Developing Countries in Climate Change,' in Climate Policy for the 21st Century: Meeting the Long-Term Challenge of Global Warming, (ed.) D. Michel. Center for Transatlantic Relations, Johns Hopkins University, Baltimore, MD, 233-264.

Gupta, J. \& van Asselt, H. 2006, 'Helping Operationalize Article 2: A Transdisciplinary Methodological Tool for Evaluating When Climate Change is Dangerous,' Global Environmental Change, vol. 16, 83-94.

Henry, A. D. 2000, 'Public Perceptions of Global Warming,' Human Ecology Review, vol. 7, 25-30. Intergovernmental Panel on Climate Change (IPCC). 2001a, Climate Change 2001: A Summary for Policymakers. Cambridge University Press, Cambridge \& New York. 2007a, Climate Change 2007: Synthesis Report. Cambridge, UK, Cambridge University Press, Cambridge \& New York. 2007b, Climate Change 2007: The Physical Science Basis. Contribution of Working Group I to the

\footnotetext{
${ }^{18}$ This is not meant to say that there aren't fundamental issues of justice inherent to the climate change problematique, there are. However, it is difficult to see justice as a primary vehicle for international political cooperation and political change to address climate change.
} 
Fourth Assessment Report of the Intergovernmental Panel on Climate Change, (eds) S. Solomon, D. Qin, M. Manning, Z. Chen, M. Marquis, K. B. Averyt, M. Tignor \& H. L. Miller (eds). Cambridge University Press, Cambridge \& New York.

2007c, 'Summary for Policymakers,' in Climate Change 2007: The Physical Science Basis. Contribution of Working Group I to the Fourth Assessment Report of the Intergovernmental Panel on Climate Change, (eds) S. Solomon, D. Qin, M. Manning, Z. Chen, M. Marquis, K.B. Averyt, M.Tignor \& H. L. Miller. Cambridge University Press, Cambridge \& New York. 2007d, Climate Change 2007: Impacts, Adaptation and Vulnerability. Contribution of Working Group II to the Fourth Assessment Report of the Intergovernmental Panel on Climate Change, (eds) M. Parry, O. Canziani, J. Palutikof, P. van der Linden \& C. Hanson. Cambridge University Press, Cambridge \& New York.

Jacoby, H. D. 2004, 'Informing Climate Policy Given Incommensurable Benefits Estimates,' Global Environmental Change, vol. 14, 287-297.

Jamieson, D. 1992, 'Ethics, Public Policy and Global Warming,' Science, Technology, and Human Values, vol. 17, 139-153.

Kanie, N., Nishimoto H., Hijioka, Y. \& Kameyama, Y. 2010, 'Allocation and Architecture in Climate Governance Beyond Kyoto: Lessons from Interdisciplinary Research on Target Setting,' International Environmental Agreements, vol. 10, 299-310.

Kasperson, R. E., Renn, O., Slovic, P., Brown, H. S., Emel, J., Goble, R., Kasperson, J. \& Ratick, S. 1988, 'The Social Amplification of Risk: A Conceptual Framework,' Risk Analysis, vol. 8, 177-187.

Keller, U. 2003, 'Operationalizing Article 2 of the UNFCCC,' Development Alternatives Newsletter, vol. 13, no. 11, 19-20.

Kenny, G. J., Warrick, R. A., Campbell, B. D., Sims, G. C., Camilleri, M., Jamieson, P. D. and Mitchell, N.D. 2000, 'Investigating Climate Change Impacts and Thresholds: An Application of the CLIMPACTS Integrated Assessment Model for New Zealand Agriculture,' Climatic Change, vol. 46, 91-113.

Laidler, G.J. 2006, 'Inuit and Scientific Perspectives on the Relationship Between Sea Ice and Climate Change: The Ideal Complement?,' Climatic Change, vol. 78, 407-444.

McDaniels, T., Lawrence J. A., and Slovic, P. 1996, 'Perceived Ecological Risks of Global Change: A Psychometric Comparison of Causes and Consequences,' Global Environmental Change, vol. 6, 159-171.

Meira Filho, L. G. \& Gonzalez Miguez, J. D. 2000, Note on the Time-dependent Relationship Between Emissions of Greenhouse Gases and Climate Change. Ministry of Science and Technology, Federal Republic of Brazil, Brazilia. Online, available: http://unfccc.int/resource/brazil/documents/proposta.pdf [Accessed 1 Sep 2011].

Melkas, E. 2002, 'Sovereignty and Equity Within the Framework of the Climate Regime,' Review of European Community and International Environmental Law, vol. 11, no. 2, 115-128.

Meyer, A. 2000, Contraction and Convergence. The Global Solution to Climate Change. Green Books, London.

Meyer, L. H. \& Roser, D., 2006, 'Distributive Justice and Climate Change: The Allocation of Emissions Rights,' Analyse and Kritik, vol. 28, 222-48.

Moss, R.H. and Schneider, S.H. 2000, 'Uncertainties in the IPCC TAR: Recommendations to Lead Authors for More Consistent Assessment and Reporting,' in Guidance Papers on the Cross Cutting Issues of the Third Assessment Report of the IPCC, (eds) R. Pachauri, T. Taniguchi \& K. Tanaka. World Meteorological Organization, Geneva, 33-51.

Oberheitmann, A. 2011, 'A New Post-Kyoto Climate Regime Based on Per-capita Cumulative CO2emission Rights - Rationale, Architecture and Quantitative Assessment of the Implication for the CO2-emissions from China, India and the Annex-I countries by 2050,' Mitigation and Adaptation Strategies for Global Change, vol. 15, 137-168.

OECD 2003, 'Development and Climate Change in Nepal: Focus on Water Resources and Hydropower,' Document COM/ENV/EPOC/DCD/DAC(2003)1/FINAL. OECD Environment Directorate, Paris. Online, available: http://www.oecd.org/dataoecd/6/51/19742202.pdf [Accessed 1 Sep. 2011].

Oppenheimer, M. 2005, 'Defining Dangerous Anthropogenic Interference: The Role of Science, the Limits of Science,' Risk Analysis vol. 25, 1399-1407.

Oppenheimer, M. \& Petsonk, A. 2003, 'Global Warming: The Intersection of Long-term Goals and Nearterm Policy,' Climate Policy for the 21st Century: Meeting the Long-Term Challenge of Global Warming, (ed.) D. Michel, Center for Transatlantic Relations, Johns Hopkins University, Baltimore, MD, 79-112.

Ott, K., Klepper, G., Lingner, S., Schäfer, A., Scheffran, J. \& Sprinz, D. 2004, 'Reasoning Goals of Climate Protection,' Specification of Article 2 UNFCCC. Berlin: Umweltbundesamt. 
Page, E. 2008, 'Distributing the Burdens of Climate Change,' Environmental Politics, vol. 17, 556-75.

Parry, M. L., Carter, T. \& Hulme, M. 1996, 'What is Dangerous Climate Change?,' Global Environmental Change, vol. 6, 1-6.

Patwardhan, A., Schneider, S. H. and Semenov, S. M. 2003, 'Assessing the Science to Address UNFCCC Article 2,' IPCC Concept Paper. Online, available: http://www.fiacc.net/data/cct3 Art 2 key vulnerabilities.pdf [Accessed 1 Sep 2011].

Paavola, J. \& Adger, W. N. 2006, 'Fair Adaptation to Climate Change,' Ecological Economics, vol. 56, no. 4, 594-609.

Pearce, D. W. 2003, 'The Social Cost of Carbon and its Policy Implications,' Oxford Review of Economic Policy, vol. 19, 362-384.

Pielke Jr, R., Prins, G., Rayner, S. \& Sarewitz, D., 2007, 'Lifting the Taboo on Adaptation,' Nature, vol. 445, 597-598.

Pittini, M. \& Rahman, M. 2004, 'Social Costs of Carbon,' in The Benefits of Climate Policies: Analytical and Framework Issues,(eds) J. Corfee-Morlot \& S. Agrawala. OECD, Paris, 189-220.

Prins, G. \& Rayner, S., 2007, The Wrong Trousers: Radically Rethinking Climate Policy. MacKinder Programme for the Study of Long Wave Events, LSE and Institute for Science, Innovation \& Society, University of Oxford, Oxford. Online, available: http://www.sbs.ox.ac.uk/centres/insis/Documents/TheWrongTrousers.pdf [Accessed 22 June 2011].

Raper, S., Wigley, T. M. L. \& Warrick, R. A. 1996, 'Global Sea Level Rise: Past and Future,' in Sea Level Rise and Coastal Subsidence: Causes, Consequences and Strategies, (eds) J. D. Milliman \& B. U. Haq. Kluwer Academic Publishers, Boston, MA.

Rawls, J. 1971, A Theory of Justice. Oxford University Press, Oxford. 1999, The Law of Peoples. Harvard University Press, Cambridge, MA

Rayner, S. \& Malone, E. L. (eds) 1998, Human Choice and Climate Change (Vol. 1: The Societal Framework). Battelle Press, Washington, DC.

Rayner, S. 2010, 'How to Eat an Elephant: A Bottom-up Approach to Climate Policy, Climate Policy, vol. 10, 615-621.

Schellnhuber, H. J., Cramer, W., Nakićenović, N., Yohe, G. \& Wigley, T. M. L. (eds). 2006, Avoiding Dangerous Climate Change. Cambridge University Press, Cambridge.

Schneider, S. H. 2001, 'What is 'dangerous' climate change?,' Nature, vol. 411, 17-19. 2004, 'Abrupt Non-linear Climate Change, Irreversibility and Surprise,' Global Environmental Change, vol. 14, 245-258.

Shue, H. 1999. 'Global Environment and International Equity,' International Affairs vol. 75, 531-45. 2011, 'Face reality? After You! - A Call for Leadership on Climate Change,' Ethics and International Affairs, vol. 25, 17-26.

Stern, N. 2007, The Economics of Climate Change: The Stern Review. Cambridge University Press, Cambridge. 2009, The Global Deal: Climate Change and the Creation of a New Era of Progress and Prosperity. Public Affairs, New York.

Torvanger, A., Twena, M. \& Vevatne, J. 2004, 'Climate Policy Beyond 2012: A Survey of Long-Term Targets and Future Frameworks,' CICERO Report 2004:02. CICERO, Oslo.

United Nations. 1992, United Nations Framework Convention on Climate Change (UNFCCC). FCCC/INFORMAL/84, GE.05-62220 (E) 200705. Online, available: http://unfccc.int/resource/docs/convkp/conveng.pdf [Accessed 5 May 2011]. 1998, Kyoto Protocol. Accessed May 5, 2010 at: http://unfccc.int/resource/docs/convkp/kpeng.pdf.

United Nations. 2009, Copenhagen Accord. Online, available: http://unfccc.int/resource/docs/2009/cop15/eng/107.pdf [Accessed 24 May 2011].

United Nations Development Program (UNDP) 1994, Human Development Report 1994. Oxford University Press, New York 2007, 'Summary_Human Development Report 2007/2008,' Fighting Climate Change: Human Solidarity in a Divided World. Palgrave-MacMillan, New York.

United Nations Environment Programme (UNEP) 2010. The Emissions Gap Report: Are the Copenhagen Accord Pledges Sufficient to Limit Global Warming to $2^{\circ} \mathrm{C}$ or $1.5^{\circ} \mathrm{C}$ ?. Technical Report, Nairobi, Kenya: United Nations Environment Programme. Online, available: http://www.unep.org/publications/ebooks/emissionsgapreport [Accessed 22 June 2011]

United Nations Framework Convention on Climate Change (UNFCCC) 2010a. Copenhagen Accord. In: Report of the Conference of the Parties on its Fifteenth Session, held in Copenhagen from 7 to 19 December 2009, Addendum, Part Two: Action Taken by the Conference. FCCC/CP/2009/11/Add.1, decision 2/CP.15. United Nations Framework Convention on Climate Change, Bonn, Germany. Online, available: 
http://unfccc.int/resource/docs/2009/cop15/eng/11a01.pdf [Accessed 14 June 2011]. 2010b. Outcome of the Work of the Ad Hoc Working Group on Long-term Cooperative Action Under the Convention (The Cancun Agreements for the AWG-LCA). United Nations Framework Convention on Climate Change, Bonn, Germany. Online, available:

http://unfccc.int/files/meetings/cop 16/application/pdf/cop16 lca.pdf [Accessed 14 June 2011]. 2010c. The Cancun Agreements: Outcome of the work of the Ad Hoc Working Group on Longterm Cooperative Action under the Convention. United Nations Framework Convention on Climate Change, Bonn, Germany. Online, available: http://unfccc.int/resource/docs/2010/cop16/eng/07a01.pdf [Accessed 22 June 2011].

Van Aalst, M. K., Cannon, T. \& Burton, I. 2008, 'Community Level Adaptation to Climate Change: The Potential Role of Participatory Community Risk Assessment,' Global Environmental Change, vol. $18,165-179$.

Wigley, T. M. L. 1995, 'Global Mean Temperature and Sea Level Consequence of Greenhouse Gas Concentrations Stabilization,' Geophysical Research Letters, vol. 22, 45-48.

1999, The Science of Climate Change: Global and US Perspectives. Pew Center for Climate Change, Washington, DC.

Wilbanks, T. J. \& Robert K. 1999, 'Global Change in Local Places: How Scale Matters,' Climatic Change, vol. 43, 601-628.

World Resources Institute (WRI) 2010, Reflections on the Cancun Agreements. WRI Working Paper, Washington, DC. Online, available: http://pdf.wri.org/reflections on cancun agreements.pdf [Accessed 22 June 2011]. 